\title{
FUSIBILITY OF GRAPHITE ASH AND ITS INFLUENCE ON THE REFRACTORINESS OF BOND CLAY. ${ }^{1}$
}

By M. C. Booze.

The ash content of graphites used in the manufacture of graphite crucibles is considered to be detrimental both because it lowers the carbon content and because, upon ignition of the carbon, it exerts a fluxing action upon the body.

The various crucible graphites vary considerably in the per cent of ash which they contain. The Ceylon variety is probably the purest of the crucible grades, the lump containing from 2 to I 5 per cent of ash and the chip from 5 to 30 per cent. The domestic graphites contain from io to is per cent of ash according to the process of milling and the specifications of the user. The average ash content of graphites used in the manufacture of crucibles is probably between ro and 15 per cent. The ash is minutely associated with the graphite and of course can exert no fluxing action upon the body until the carbon is burned out. In a crucible, therefore, the fluxing action, if there be any, begins on the surface of the crucible, where oxidation first takes place, and proceeds inward only as fast as the ash is formed. The production of a dense skin on the crucible, which would accompany the softening of the clay and ash mixture, would retard the further penetration of gases and the combustion of the graphite so that the fluxing action of the ash would be materially retarded.

\section{Laboratory Tests.}

In the investigation, the softening points of graphite ashes and of ash and clay mixtures were determined in order to learn the extreme effect of the ash in lowering the refractoriness of graphite crucibles. The various graphites, which had been previously collected for experimental work on crucibles, were sampled by quartering down to about 200 grams. Each sample was then

${ }^{1}$ By permission of the Director, U. S. Bureau of Mines. 
heated to $900^{\circ} \mathrm{C}$ in an electric furnace and held under a gentle current of air until all of the carbon had been burned out. Part of the ash so obtained was then mixed with dextrin and molded into cones of the same size and shape as the Orton standard cones. Other cones were made by mixing the ash with Mississippi bond clay in the ratio of 12 parts ash to 88 parts clay, or about the same proportion that the average crucible would show upon ignition of the graphite. The softening points of the cones were then determined against standard cones in a gas-fired pot furnace. The softening point of the clay used was determined in the same manner. The results are given in the table on the following page.

As a rule the ash from the Alabama graphite was more refractory than any of the others. The Ceylon and Canadian graphites gave ashes which were relatively quite fusible. The ash from the Pennsylvania graphite also had a low softening point.

The mixtures of clay and ash did not show the variation in softening points that might be expected from the results with the ashes alone. With the exception of three of the mixtures, a variation of only three cones was noted. The mixtures containing the ash from Alabama graphite show the highest softening points while the mixture containing ash from Canadian graphite gave the lowest softening point. The ash from Ceylon graphite, while showing a low softening point itself, gave a high softening point when mixed with clay. There appears to be little relation between the softening point of the ash and the softening point of the clay and ash mixtures.

None of the mixtures and only three of the ashes show softening points low enough to be effective at brass melting temperatures. Fourteen of the graphites gave ashes which would soften at steel melting temperatures while eight did not. Nine of the clay-ash mixtures softened at points corresponding to the highest temperatures used in crucible steel melting, three were low enough to be effective at the average temperatures used, and ten were above maximum temperature-assuming that cone 26 corresponds to a temperature of $1600^{\circ} \mathrm{C}$, as given in the latest determinations. 


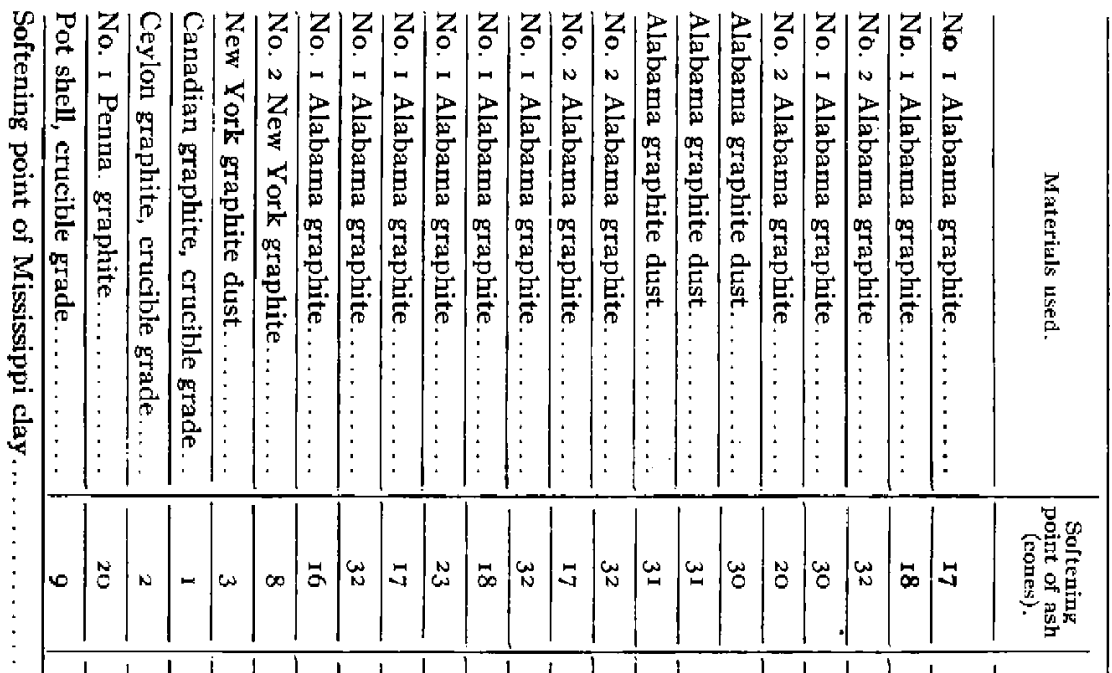

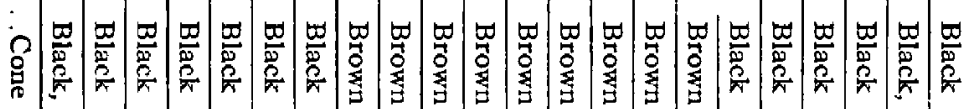
क 宽

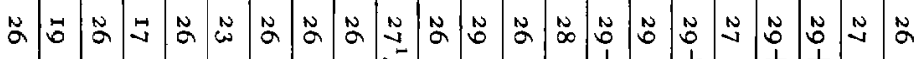

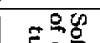

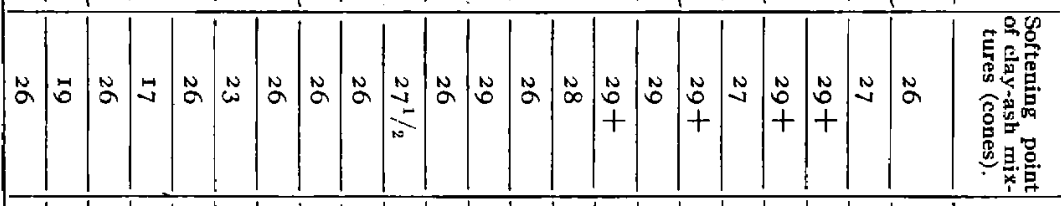

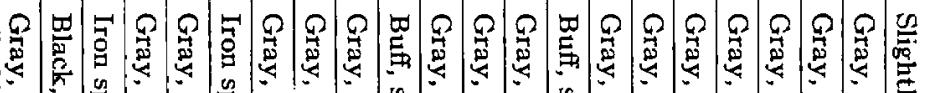

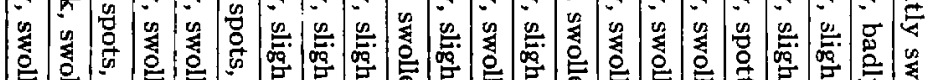

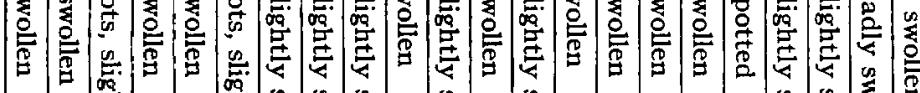

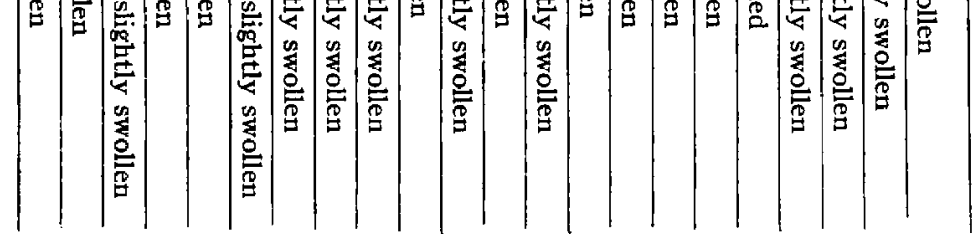


A degree of softening below that obtained in the clay-ash cones would undoubtedly be detrimental to a crucible, but since the clay and ash in a crucible are not so intimately blended as in the cones, the softening point of the crucible mixture may even be higher than herein registered. The clay used for this work showed a softening point of cone 30 -which is somewhat low for steel crucibles. Clays of the type used for steel crucibles do not vary widely in their composition and the use of a more refractory bond clay should still further raise the softening points of the mixtures.

\section{Conclusions.}

The softening point of a graphite ash is not a true criterion of its action in a crucible body.

The tendency of graphite ash to lower the refractoriness of a crucible is not evident at brass-melting temperatures and would seldom be detrimental even in steel melting crucibles.

The ash from Alabama graphite is less effective as a flux than the ashes from the Ceylon, Canadian, Pennsylvania or New York graphites.

Bureau OF Mines,

Mining Experiment Station,

Colvmaus, Ohio. 